\title{
Experimental investigation on buckling of GFRP cylindrical shells subjected to axial compression
}

\author{
Venkata Narayana Yenugula ${ }^{1}$, Bhasker Perumandla ${ }^{2}$, Ravinder Reddy Pinninti ${ }^{3}$ \\ Markandeya Ravvala ${ }^{4}$ \\ 1 (Department of Mechanical Engineering, Sree Nidhi Institute of Science \& Technology \\ Yamnampet, Ghatkesar, Andhra Pradesh, India. PIN 501301) \\ *Corresponding Author Email ID: vnyenugula@gmail.com \\ 2(Department of Mechanical Engineering, Sree Nidhi Institute of Science \& Technology \\ Yamnampet, Ghatkesar, Andhra Pradesh, India. PIN 501301) \\ 3Chaitanya Bharathi Institute of Technology, Gandipet, Hyderabad \\ 4JNTUH, kukatpally, Hyderabad, Andhra Pradesh, India
}

\begin{abstract}
Composite cylindrical shells are being used in submarine, underground mines, aerospace applications and other civil engineering applications. Thin cylindrical shells are more prone to fail in buckling rather than material failure. An experimental study on buckling of glass fiber reinforced plastics layered composite cylindrical shells under displacement and load controlled static axial compression are reported The experimental results are compared with general purpose finite element program (ANSYS). Limit point loads evaluated for geometric imperfection magnitudes shows an excellent agreement with experimental results which clearly indicates the confidence gained on the numerical results presented. Present study finds direct application to qualitatively investigate the influence of geometric imperfection on other advanced grid-stiffened structures.
\end{abstract}

Keywords: Composite, cylindrical shell, finite element, geometric imperfection, nonlinear buckling

\section{Introduction}

Thin walled cylindrical shells find wider applications as primary structural members in various fields of engineering such as civil, mechanical, aerospace and nuclear engineering fields. Stiffened and unstiffened shells made up of metallic and laminated composite materials (large diameter to thickness ratio) are extensively used in underwater, surface, air and space vehicles as well as in construction of pressure vessels, storage vessels, storage bins and liquid storage tanks. The contribution of geometric imperfections due to manufacturing processes takes dominant role in decreasing the buckling load of cylindrical shells. Buckling is often viewed as the controlling failure mode of these structures due to its relatively small thickness of these structural members. It is therefore essential that the buckling strength of the thin shells along with knowledge of its post buckling behavior has been the subject of many researchers in both analytical and experimental investigations. The problem of cylindrical shell buckling subjected to axial compressive loads has been investigated by various researchers ${ }^{[1-10]}$ using approximate analytical methods as well as finite element methods. Theoretically evaluated classical buckling load is generally much higher than the actual buckling load of the cylindrical shell and a knock-down factor is introduced to evaluate a better approximation based on an extensive experimental investigation. Fischer ${ }^{[11]}$, Yamaki and Kodama ${ }^{[12]}$, investigated the effect of bending stresses and pre-buckling deformations and emphasized that the effect of pre-buckling deformations was not a primary reason for the difference between the classical prediction and the experimental results. The pioneering contributions of von Karman and Tsien ${ }^{[13]}$, Donnell and Wan ${ }^{[14]}$, Koiter et al. ${ }^{[15]}$, Budiansky and Hutchinson ${ }^{[16]}$ on cylindrical shell buckling shows that initial geometric imperfections is the single dominant factor for contributing the discrepancy between theory and experiments. Present study makes a modest attempt to accurately evaluate the limit point load of an isotropic and composite; imperfect cylindrical shells by means of non-linear buckling analysis as well as post-buckling analysis approaches by using general purpose finite element software (ANSYS) ${ }^{[17]}$. A generalized procedure is employed here which can be extended to investigate the behavior of any other modes of practical interest (for example ovality mode for long cylinders) to any given choice of imperfection shapes can be modeled more accurately.

\section{Experimental Description}

A detailed experimental study was undertaken to investigate the buckling behavior of composite GFRP cylindrical shells subjected to in plane compressive load. To meet the wide range of needs which may be required in fabricating composites, the industry has evolved over a dozen separate manufacturing processes as 
well as a number of hybrid processes. Each of these processes offers advantages and specific benefits which may apply to the fabricating of composites. Hand lay-up and filament winding are two basic processes for fabricating cylindrical shells. The hand lay-up process is the oldest, simplest, and most labor intense fabrication method. In hand lay-up method liquid resin is placed along with reinforcement (woven glass fiber) against finished surface of a mandrel. The resin serves as the matrix for the reinforcing glass fibers. In present study the specimens are manufactured using a commercially available filament winding machine. An available mandrel as shown in figure 1 of $300 \mathrm{~mm}$ outer diameter was used to make the cylindrical shell specimen of $300 \mathrm{~mm}$ height and $300 \mathrm{~mm}$ inner diameter. Before winding the raving's around the cylindrical mandrel, the mandrel surface is thoroughly cleaned with acetone to remove any dust, dirt or rust. Then, one layer of Teflon coated release film is placed over the mould surface of the mandrel and the reference line for $0^{\circ}$ in the axial direction of the mandrel is marked on the surface. 1200 tex direct roving's of untwisted continuous filament of Boron free "E" - glass and isophthalic polyester matrix was used for preparing the above cylindrical shell specimens. The mandrel with shell was kept rotating for a minimum of 48 hours before being extracted and cut to exact cylindrical shell shape for testing. The experimental buckling tests were performed on the cylindrical shells under axial compression using a loading rig.

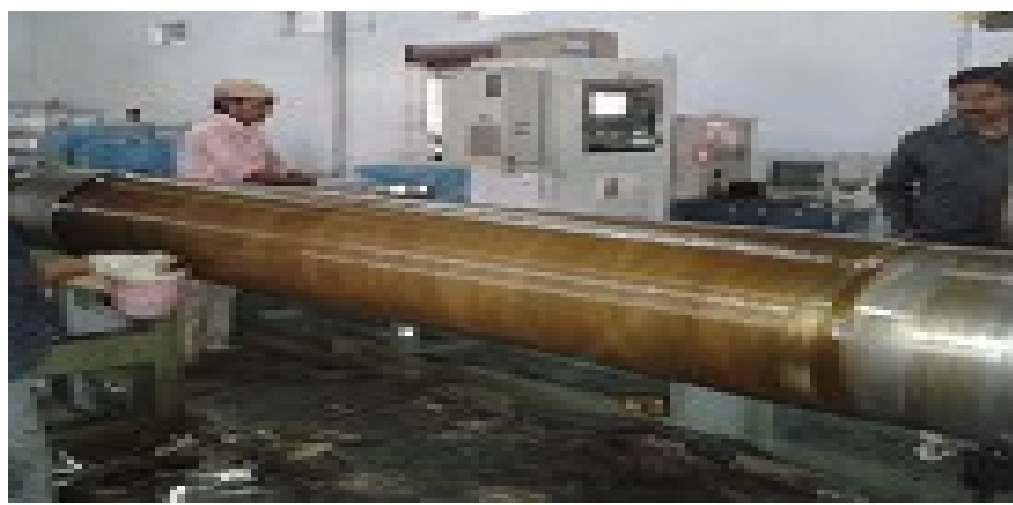

Fig.1. Mandrel with release film

\section{Specimen Design}

The size of the GFRP thin cylindrical shells were designed parametrically and chosen as $300 \mathrm{~mm}$ effective length, $1.5 \mathrm{~mm}$ thickness with $300 \mathrm{~mm}$ diameter. The $+45^{\circ} /-45^{\circ}$ ply sequence was taken in composite laminated cylindrical shell analysis. The linear and nonlinear buckling analysis was performed for the above designed size of the composite cylindrical shell. The geometric imperfections were taken in nonlinear and post buckling analysis. The capacity of the testing machine was chosen based on the linear and non linear buckling analysis. The geometry of the cylindrical shell is shown in figure 2 .

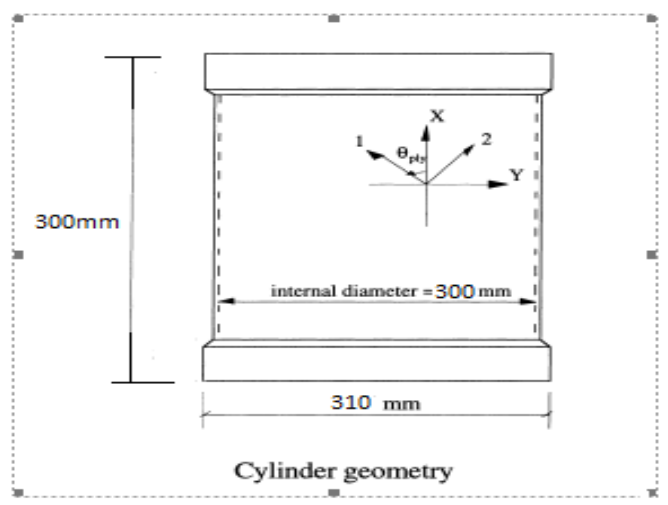

Fig.2. Cylindrical Shell Geometry

\section{Specimen Preparation}

The purpose build mandrel of $300 \mathrm{~mm}$ diameter was used to make the cylindrical shell of $1500 \mathrm{~mm}$ length with $1.5 \mathrm{~mm}$ thickness. The cured cylindrical shell was extracted from the mandrel using specially designed hydralic ficture. Five number of specimens with each $300 \mathrm{~mm}$ length cylindrical shell were prepared for testing. The $+45^{\circ}-45^{\circ}$ ply orientation (winding angle in filament winding machine) was maintained with 
1200 tex direct roving's and isophthalic polyester matrix to get the $1.5 \mathrm{~mm}$ thickness cylindrical shell specimens. The end parts were significantly thicker than the middle part as shown in figure 3 to ensure zero radial displacements along the edges and to minimize the risk of local splitting or delamination at the boundaries. The specimens were accurately sized to $300 \mathrm{~mm}$ length on lathe machine and thickness was measured using specially designed vernier micrometer. The measured thickness was shown in table 1. For the given mechanical properties of the manufactures of fiber and resin the laminate properties, were calculated. The theoretically calculated mechanical properties of the laminate for evaluating buckling loads using finite element program are shown in Table 1. The edges of the cylindrical shell are fitted into circular, $10 \mathrm{~mm}$ deep grooves with in the circular steel plates thus leaving a free unsupported length $280 \mathrm{~mm}$ between the inner faces of these plates as shown in figure 4. The grooves were filled with a mixture of resin and quartz powder. Measurement of cylinder thickness was carried out using vernier micrometer mounted on specially designed bracket.

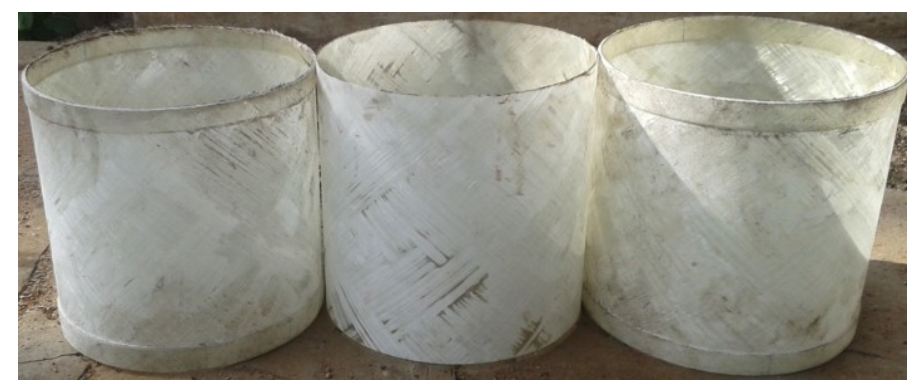

Fig.3. Sized Cylindrical Shells

Table 1. Mechanical properties of composite laminate

\begin{tabular}{|l|l|l|l|}
\hline \multirow{2}{*}{ S.No. } & Composite material properties (E-glass/polyester) \\
\cline { 2 - 4 } & Property & Direction & Value \\
\hline 1 & Longitudinal modulus (GPa) & $E_{11}$ & 16.4 \\
\hline 2 & Transverse modulus(GPa) & $E_{22}$ & 12.7 \\
\hline 3 & Shear modulus (GPa) & $G_{12}$ & 3.1 \\
\hline 4 & Poisson's ratio & $v_{12}$ & 0.20 \\
\hline
\end{tabular}

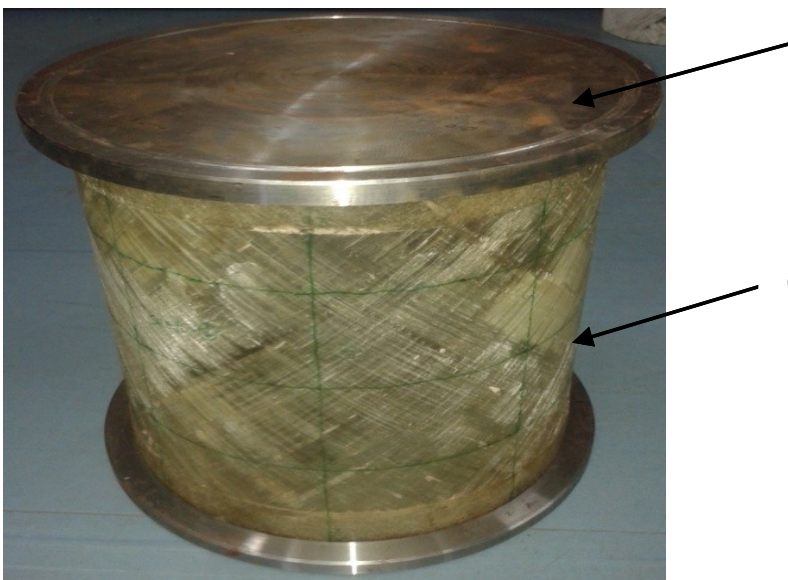

Grooved plates

GFRP Cylindrical shell

Fig.4. Cylindrical shells with assembly

\section{Finite Element Analysis}

The thin cylindrical GFRP shell was modeled with 8-noded shell element with six degrees of freedom at each node which is referred as SHELL281. In ANSYS, a subspace iteration technique is employed to extract the eigen values and the corresponding eigen vectors. Geometric non-linearity is considered by using the vonKarman strain-displacement relations, where the moderately large rotations and displacements of the order of characteristic dimension of the problem are allowed. Fig. 5 shows the mesh convergence study obtained from the linear buckling analysis and an element size of $10 \mathrm{~mm}$ is chosen for all (for non-linear buckling analysis) the numerical results discussed in this study. 


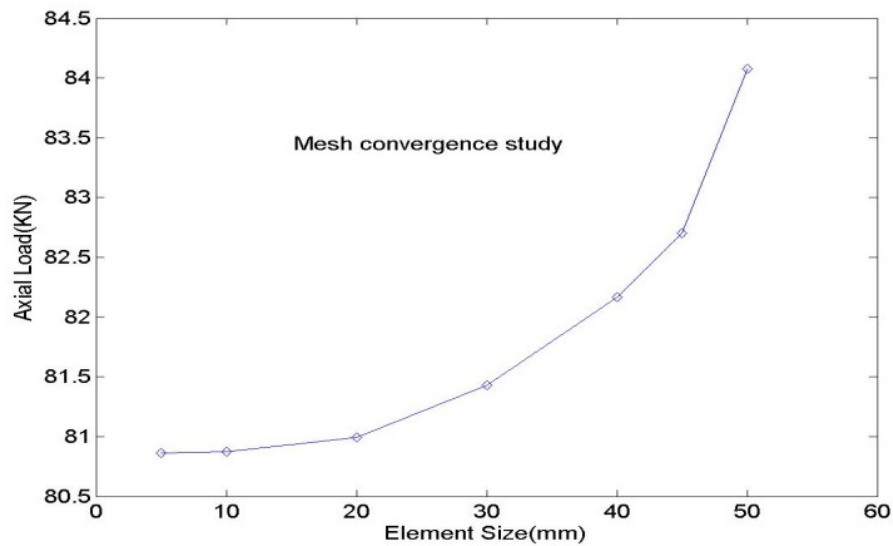

The adopted geometrical values of the composite cylindrical shell for this study are: radius of the cylindrical shell is $150 \mathrm{~mm}$, thickness of the cylindrical shell is $1.5 \mathrm{~mm}$, length of the cylindrical shell is $300 \mathrm{~mm}$, and material properties are shown in Table 1. The critical buckling load obtained from the linear buckling (eigen value) analysis is $80.87 \mathrm{KN}$. The nonlinear buckling load (limit point load) using imperfection magnitude predicted using finite element analysis is $59.33 \mathrm{KN}$.

\section{Buckling Tests}

The set up for the buckling test is shown in fig.5a. The cylindrical shell was subjected to static axial compression under load control by a hydraulically operated compression testing machine of $100 \mathrm{KN}$ capacity. The specimen was placed between the two heads of the compression testing machine, which has a moving bottom head and a fixed top head. In order to accurately ascertain the axial load applied on the specimen, a load cell was placed between the specimen and the top head. When the load reached $56 \mathrm{KN}$, the shell buckled suddenly with a loud noise. The buckled mode shape of the cylindrical shell specimen after post buckling load is shown in Fig.6b.

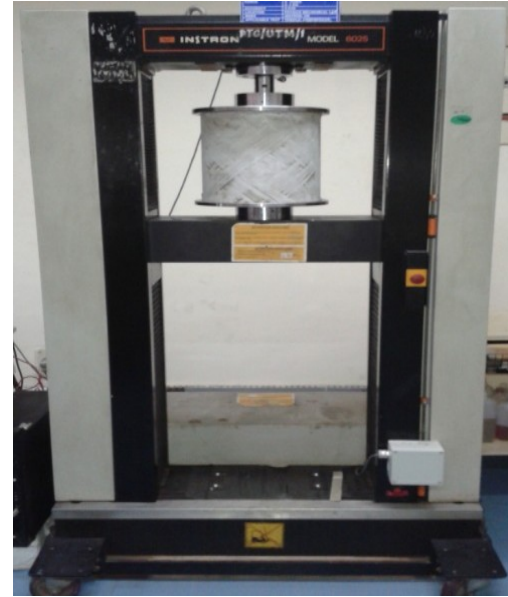

Fig.6a. Shell before test

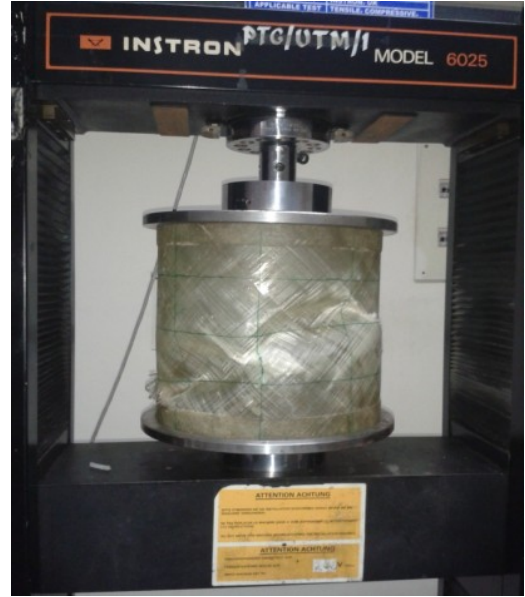

Fig.6b Buckled shell after test

Table 2. Buckling loads and buckling displacements cylindrical shells

\begin{tabular}{|c|c|c|c|c|c|}
\hline \multicolumn{2}{|c|}{ Experimental load } & \multirow{2}{*}{$\begin{array}{l}\text { Maximum } \\
\text { Buckling Load } \\
(\mathrm{KN})\end{array}$} & $\begin{array}{l}\text { Average } \\
\text { Buckling Load } \\
(\mathrm{KN})\end{array}$ & \multirow{2}{*}{$\begin{array}{l}\text { Displacement }(\mathrm{mm}) \\
\text { at limit point }\end{array}$} & $\begin{array}{l}\text { Average } \\
\text { Displacement }(\mathrm{mm})\end{array}$ \\
\hline \multirow{4}{*}{$\begin{array}{l}\text { Experimental } \\
\text { load }\end{array}$} & Specimen 1 & & \multirow[b]{4}{*}{52.00} & & \multirow[b]{4}{*}{2.30} \\
\hline & Specimen 2 & 52.00 & & 2.13 & \\
\hline & Specimen 3 & 51.00 & & 2.62 & \\
\hline & Specimen 4 & 49.00 & & 2.02 & \\
\hline
\end{tabular}

Table 2 shows the experimental limit point buckling load and the corresponding displacement. The average load observed for four cylindrical shells is around $52 \mathrm{KN}$. Figure 7 shows the load displacement verses displacement graph which is directly obtained from the Universal Testing Machine for the specimen-1. 


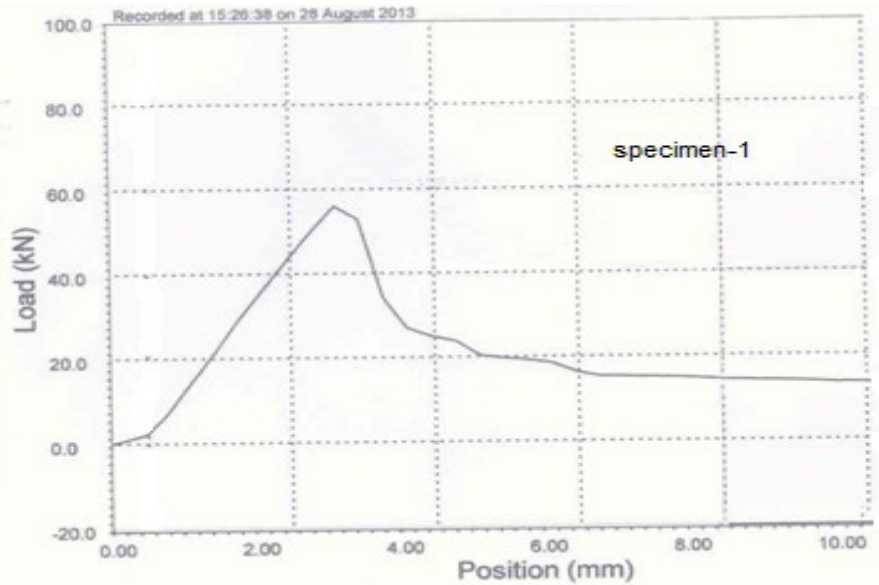

Fig.7 Graph of Load vs. Displacement

VII. Results And Discussions

The linear buckling (eigen value) load evaluated for the composite cylindrical shell on the basis of finite element analysis is $80.87 \mathrm{KN}$ and the limit point load obtained from nonlinear buckling analysis for imperfection magnitude 0.1 of thickness is $59.33 \mathrm{KN}$ against the experimental value of $56.00 \mathrm{KN}$. Limit point loads evaluated for geometric imperfection magnitudes shows an excellent agreement with experimental results. The experimental results of sample1 were compared with the finite element analysis, post buckling results and shows excellent agreement which are shown in figure 8.

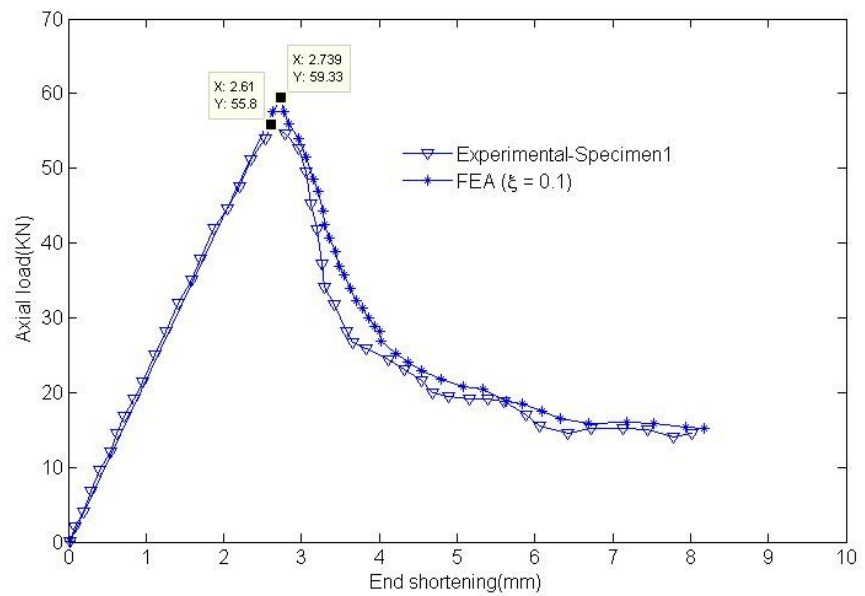

Figure 8

\section{Conclusion}

The linear and nonlinear buckling analysis of composite cylindrical shell were performed using generalized finite element program ANSYS. The cylindrical shell specimens were manufactured accurately using filament winding machine and these samples were tested under compressive loads. The experimental results were compared with general purpose finite element program (ANSYS) results. Limit point loads evaluated for geometric imperfection magnitudes shows an excellent agreement with experimental results which clearly indicates the confidence gained on the numerical results presented. Present study finds direct application to qualitatively investigate the influence of geometric imperfection on other advanced grid-stiffened structures.

\section{REFERENCES}

[1]. Lorenz, Z., (1908) Achsensymmetrische Verzerrungen in dunwandigen Hohlzylinder. Z. Ver. Deut. Ingr. 52, 1766-1793

[2]. Timoshenko, S.P., (1910) Einige Stabilitatsrobleme der Elastizatstheorie. Z. Math. Phys. 58, $337-357$.

[3]. South well, R.V., (1914) On the general theory of elastic stability. Phil. Trans. Royal Soc., London, Series A, 213, 187-202.

[4]. Robertson, A., (1929) The Strength of tubular struts. ARC Report and Memorandum No. 1185

[5]. Flugge, W., (1932) Die Stabilitat der Kreiszylinderschalen. Ingenieur-Archiv. 3,463-506.

[6]. Lundquist, E.E., (1933) Strength test of thin-walled duralumin cylinders in compression. NACA Tech. Note, No 473.

[7]. Wilson, W.M., and Newmark, N.M., (1933) The strength of thin cylindrical shells as columns. Bulletin No 255, Eng. Experimental Station, Univ of Illinois. 
[8]. Stein, M., (1962) the effect on the buckling of perfect cylinders of pre-buckling deformations and stresses induced by edge support, in Collected Papers on Instability of Shell Structures, NASA Tech. Note, No. D- 1510, 217-226.

[9]. Hoff, N.J., and Rehfield, W., (1965) Buckling of axially compressed cylindrical shells at stresses smaller than the classical critical value. J. Appl. Mech., ASME 32, 542-546.

[10]. Almroth, B.O., (1966) Influence of edge conditions on the stability of axially compressed cylindrical shells. AIAA J., II (II), 134140.

[11]. Fischer, G., (1965) Influence of boundary conditions on stability of thin-walled cylindrical shells under axial load and internal Pressure. AIAA J. 3,736-738.

[12]. Yamaki, N., and Kodama, S., (1972) Buckling of circular cylindrical shells under compression-report 3: solutions based on the Donnell type equations considering pre-buckling edge rotations. Report of the lnst. of High Speed Mech., No. 25, Tohoku Univ., 99-141.

[13]. Von Karman, T., and Tsien, H.S., (1941) The buckling of thin cylindrical shells under axial compression. J. Aerospace Sci. 8, 303312.

[14]. Donnell, L.H., and Wan, C.C., (1950) Effect of imperfections on buckling of thin cylinders and columns under axial compression. J. Appl. Mech., ASME 17(1), 73-83.

[15]. Koiter, W.T., Elishakoff, I., Li, Y.W., and Starnes, Jr. JH. (1994) Buckling of an axially compressed cylindrical shell of variable thickness, Int. J. Solids Struct. 31(6), 797-805.

[16]. Budiansky, B., and Hutchinson, J.W., (1966) A survey of some buckling problems. AIAA J. 4(9), 15051510

[17]. ANSYS, Inc theory of reference. 